\title{
Survey into the Curricular Reform of "Sports and Health" and Its Implementation Status--Citing as an Example Five High Schools in Mianyang City in Sichuan Province of China
}

\author{
Zhihui Jing \\ University of Electronic Science and Technology of China \\ Dept. of Physical Education \\ Chengdu, China \\ E-mail: 1797349031@qq.com
}

\author{
Xiaowei Liu \\ Chengdu Sport University \\ Dept. of Foreign Languages \\ Chengdu, China \\ E-mail: 1402155087@qq.com
}

\begin{abstract}
This paper cites as an example five representative schools in Miangyang city in Sichuan province of China, namely, Mianyang Middle School, Mianyang Nanshan Middle School, Mianyang Puming Middle School, Mianyang No.1 Middle School and Mianyang Experimental High School. Literature review, questionnaire survey and expert consultation are applied to analyze the change characteristics of the curriculum "Sports and Health", investigate the curricular implementation status among high school students in the above-mentioned five schools and classify specific problems in the curricular implementation. Finally, important conclusions are drawn and focused suggestions are raised concerning feasible approaches to perfect the curricular reform of "Sports and Health", briefly referred to as sports new curricular reform in the following.
\end{abstract}

Keywords-Miangyang city; curriculum of "Sports and Health" in high schools; curricular reform; status; China

\section{INTRODUCTION}

Ever since China carried out the new reform in the fundamental education curriculum in 2001, great achievements have been made in the curricular reform of "Sports and Health". Viewed from the implementation status of the curricular reform in various Chinese cities and provinces, the sports new curricular reform is accredited with great achievements; however, it is confronted with many problems. In 2010, Mianyang city in Sichuan province began to carry out the sports new curricular reform among high schools. In the process of carrying out the new reform, a series of questions are raised. What are the new characteristics and changes for the sports new curricular reform? Is it smooth for Mianyang city to carry out the sports new curricular reform? When having classes, do teachers follow the guiding principle of "Health comes first" in the sports new curricular reform and attain the goal set for the five aspects of the sports new curricular reform? Based on the change features of the new curriculum of "Sports and Health", this paper takes as the research subject five representative schools in Mianyang city, namely, Mianyang Middle School, Mianyang Nanshan Middle School, Mianyang Puming Middle School, Mianyang No.1 Middle School and Mianyang Experimental High School.
A large amount of documents concerning the sports new curricular reform and major documents regarding domestic and foreign teaching reform of physical education are surveyed. Meanwhile, a large number of teachers and students in the five schools are interviewed to discuss the status for and problem in the implementation of the sports new curricular reform. Mathematical statistics are applied to approach and analyze the research findings. Moreover, a comparative study is made into the status of carrying out the sports new curricular reform in five schools with different backgrounds and focused suggestions are raised to direct against likely problems to provide reference for the sports new curricular reform in high schools.

\section{INTERPRETATION OF THE CHANGE FEATURES OF THE SPORTS NEW CURRICULAR REFORM}

\section{A. Designation of the Curricular Property}

When it comes to the property of the sports new curriculum, three features, namely, fundamentalness, practicability and comprehensiveness are highlighted in the "Standard for the Curriculum of 'Sports and Health' in General High Schools”.

\section{B. Brand-New Curricular Conception}

The brand-new curricular conception for the sports new curricular reform is embodied in the following four aspects. In the first place, the new curricular standard adheres to the guiding principle of "health comes first" and aims at cultivating students' sound psychology and physique and promoting their healthy growth. It gives priority to students' health, which amply manifests the national attention to students' healthy growth and sports. In the second place, the sports new curriculum strives to change the simplistic teaching method of cramming and reform the teaching approach of overemphasizing explanation and exemplification to create a favorable teaching atmosphere conducive to encourage students' active participation, spontaneous exploration and willing practice to make the curriculum keep up with the times. In the third place, the sports new curricular reform focuses on students' development, attaching importance to improving their ability in independent, explorative and cooperative learning. In the 
fourth place, the sports new curricular reform pays attention to cultivating students' sports interests and hobbies as well as their special sports skills to lay a foundation for students to engage in life-long sports.

\section{Change of the Curricular Target}

The overall target for the sports new curricular reform in high schools is to better the physical strength and sports skill, deepen the understanding of the knowledge and skill related to sports and health, master sports learning and its evaluation, consolidate the ability in sports practice and innovation, form sports interests and hobbies as well as special skills, cultivate the life-long awareness and habit, develop good psychological traits, strengthen interpersonal skills and group mentality, nurture healthy qualities, shape healthy physique, promote social responsibility for individual health and collective health, and to gradually form a healthy lifestyle and an active and energetic life attitude. Specific aims concern the five aspects of sports participation, sports skills, physical health, psychological health and social adaptation. The designation of the curricular target can help comprehensively develop students' physical quality and improve their characters and lay a solid foundation for cultivating qualified modern citizens with all-round development.

\section{Change of the Teaching Content}

In terms of the teaching content, national and folk sports activities and newly rising sports events are introduced into physical education classes. Such basic knowledge, skills and methods related to sports and health should be carefully selected to add to the teaching content as can keep up with the times and contribute to laying a foundation for students' life-long development. The specific teaching content includes compulsory and elective parts. The compulsory part is further divided into the compulsory and must part and the compulsory but optional part. The compulsory and must part involves the two areas of athletic events and physical education themes; the compulsory but optional part involves six areas of athletic events, ball events, gymnastic events, water or skating and skiing events, national and folk sports and newly-rising sports.

\section{E. Implementation of the Credit System}

It is required that high school students earn eleven credits in their three-year high school learning. (Eighteen periods of classes must be attended before one can earn one credit.) In the compulsory and must part, students are required to earn one credit in the athletic events and another one in the physical education themes; in the compulsory and optional part, students are required to select nine modules and earn nine credits.

\section{F. Change in the Evaluation Means and Contents}

The new evaluation standard concerns students' sports qualities and sports skills. Students' self evaluation, mutual evaluation among students and teachers' evaluation together determine whether the goals of the five areas are reached. A credit is awarded once a student learns a module and passes the examination, but the eleven modules must satisfy the demand of "module $1+$ module $2+\ldots$ module 11 lead to the curricular overall target of sports and health in high schools". As a result, evaluation of students' learning is chiefly the evaluation of the learning goal of each module. General evaluation contents include the evaluation of students' physical strength, the evaluation of sports knowledge and skill, the evaluation of the learning attitude and the evaluation of sports awareness and cooperative spirit (with exception to the module of health education themes).

\section{STATUS QUO OF IMPLEMENTING THE SPORTS NEW CURRICULAR REFORM IN FIVE HIGH SCHOOLS OF MIANYANG CITY}

\section{A. Physical Education Teachers' Understanding of the Goal and the Conception for the Sports New Curricular Reform}

A key factor determining the successful implementation of the sports new curricular reform is physical education teachers' understanding and internalization of the conception, content and goal of the sports new curricular reform. Interviews with and investigations into physical education teachers in the five schools lead to the conclusion that the majority of the physical education teachers express a comparatively clear understanding of the goal and conception of the sports new curricular reform, while a small number of physical education teachers express not a very clear understanding of it, but some physical education teachers even have no understanding of it, which works against the successful implementation of the sports new curricular reform.

\section{B. Implementation Status of the Teaching Content for the New Curriculum of "Sports and Health"}

It is required in the sports new curricular reform that national and folk sports activities of students' interests and the newly rising sports events be introduced to physical education classes to make them keep up with the times and lay a solid foundation for students' life-long development. However, statistics reveal that all schools under investigation just teach according to their old teaching contents and completely ignore the requirement.

\section{Implementation Status of the Specific Goals for the New Curriculum of "Sports and Health"}

Specific goals of the curriculum "Sports and Health" is further divided in the sports new curricular reform to cover the five aspects of sports participation, sports skills, physical health, psychological health and social adaptation, hoping that students can achieve a "three-dimensional health" with the body and mind adapting to social needs. However the investigation reveals that in the specific implementation process, physical education teachers cannot switch from the old teaching aim to the new one, causing the new teaching aim virtually irrelevant and oblivious. 


\section{Implementation Status of the Credit System}

Investigation into the practical implementation of the credit system reveals that the implementation status is comparatively good, with all the schools investigated having implemented the credit system according to the requirement of the new curriculum of "Sports and Health", which is very conducive to the development of the sports new curricular reform.

\section{E. Implementation Status of the Means to Examine and Evaluate the New Curricular of "Sports and Health"}

In the process of implementing the sports new curricular reform, more or less improvement has been made concerning the curricular evaluation. Major standards to examine and evaluate the teaching effect of the physical education class include students' class attendance and exercising initiative and spontaneity. Minor standards include various sports abilities, sports techniques and skills for each sport, amount of progress made in sports techniques and skills as well as students' constitutional health. The method of combining learning performance with phase evaluation which involves not only teachers' evaluation of the students but also students' self-evaluation and mutual evaluation. Students' sports performance shouldn't be evaluated with the score system; instead it should be evaluated in the grade system. And the sports performance should be evaluated annually. However investigation results reveal that the physical education teachers under investigation still stick to the old evaluation method and center on the pass score, regardless of other aspects.

\section{F. Situation Concerning the Course Selection and Class Attendance}

It is revealed through investigation that none of the five schools in Mianyang city adopts the teaching mode of conducting classes according to students' selection of their preferred sports. Curricular arrangement is still based on teachers' specialty and classes are accordingly conducted. The new teaching mode of breaking the boundary between teaching staff members and administrative staff members and forming classes according to the module selection within the same grade is totally ignored and virtually nonexistent. The teaching method doesn't change at all, neither does the teaching content.

\section{PROBLEMS IN THE IMPLEMENTATION OF THE SPORTS NEW CURRICULAR REFORM IN FIVE HigH SCHOOLS IN MIANYANG CITY}

\section{A. Students' Low Level of Sports Techniques and Skills}

Sports resources for each school are unevenly distributed. Standards for physical education lessons are not unified. To make matters worse, ever since the physical education examination is conducted among senior middle school students, physical education lessons in many schools center on training students' physical quality and preparing students for the examination, ignoring the important part of imparting the techniques and skills involved in many sports. As a result, many middle school students who have newly entered the high school enjoy quite a low level of sports techniques and skills, or even they have zero level of the sports techniques and skills. Under such circumstances, if high school students are asked to select the sports to their liking, they are very liable to make blind or wrong choices. It is quite unfavorable for teachers to organize classes after students have made their own choices.

\section{B. Shortage of Physical Education Teachers}

If students can make their own choices concerning the sports they want to pursue, one or more teachers should be assigned to each sport, and one substitute teacher should be provided in case of an emergency. For those schools that are originally short of physical education teachers, such teaching mode cannot be realized.

A survey into the ratio between physical education teachers and students among the five middle schools reveal that the ratio of Mianyang Middle School is $0.18 \%$, Mianyang Nanshan Middle School is $0.17 \%$, Mianyang No.1 Middle School is $0.15 \%$, Mianyang Puming Middle School is $0.31 \%$, Mianyang Experimental High School is $0.17 \%$. Judging by the above figures, among the five middle schools in Mianyang city, less than 0.2 physical education teachers are assigned to an average number of 100 students, which indicates a severe shortage of physical education teachers and sports resources to make possible the teaching mode of letting students choose their own sports.

\section{Specialty Over Concentration for Physical Education Teachers}

A survey into the specialty of physical education teachers for high school students of grade one reveals that among the five schools under investigation, even schools with comparatively adequate number of physical education teachers, namely Mianyang Middle School, Mianyang Nanshan Middle School, Mianyang Puming Middle School, the specialty of physical education teachers is overlapping. Most teachers specialize in athletics or basketball, while few teachers specialize in such sports as gymnastics, table tennis, badminton, volleyball, swimming and aerobics. Thus, the required level of sports techniques and skills for students' chosen sports is hard to reach within the framework of the teaching mode to let students choose their own sports and the demand of pluralistic physical education is impossible to satisfy.

\section{Severe Shortage of School Sports Apparatuses and Facilities}

A survey into the school sports apparatuses and facilities finds that the five schools are equipped with many basketball courts and table tennis platforms, one or two athletic fields, football courts, badminton halls, volleyball halls, but they have no gymnasiums, natatoriums or aerobic centers (with Mianyang Middle School being the exception and boasting one natatorium). It is clearly shown that the five schools are confronted with a severe shortage of sports apparatuses and facilities. One athletic field is impossible to satisfy the teaching demand of a school with over more than ten thousand students (at present, Mianyang Middle School 
has an overall number of 13221 students, and Mianyang Nanshan Middle School has an overall number of 11443 students). Current limited sports apparatuses and facilities is only suitable for separate classes to have regular physical education lessons and unfit for combined classes to have selected physical education lessons.

\section{E. Inadequate Attention Paid by the School Leaders}

Mianyang city is one of the education centers in Western China. The rate for high schools students to pass the college entrance examination ranks top nationwide. Mianyang city hosts many key middle schools of national or provincial level, with these schools competing and rivaling against each with their admission rate. Leaders in these schools attach great importance to students' performance in major tests and pay inadequate attention to sports. They care little about and provide no support for the sports new curricular reform.

\section{CONCLUSIONS AND SUGgESTIONS}

\section{A. Conclusions}

The curricular target is made clearer. The sports new curricular reform opposes overemphasis on knowledge dissemination and highlights the actualization of the "three-dimensional" goal of knowledge and skill, process and method, and emotional attitude and value philosophy.

The curricular structure is adjusted. The salient change of the sports new curricular reform in general high schools is that breakthroughs have been made in the curricular structure. The new curricular structure is composed of three layers. The upper layer is the learning zone, followed by the subject zone, and the lower layer is the module zone. The new curricular structure is helpful in organizing and regulating the courses in the macro level and useful in adjusting the subjects in the micro level, making the curricular structure more reasonable and better satisfy the demand of students' development.

The curricular contents are enriched. The sports new curricular reform attaches importance to change the complicated, difficult, minor old teaching contents to let students acquire more sports knowledge of their interests. Such relevant, fundamental and flexible required but optional teaching contents are added to the teaching syllabus to make it possible for students to select sports they want to pursue according to their own interests.

The curricular management is diversified. Fixed curricula and unified textbooks used to dominate the physical education. At present, a national-level, local-level and school-level triple management mode is emphasized to bring into full play the initiative of local and school authorities and render the education more focused and purposeful.

The curricular evaluation is diversified. Discrimination and selection are overemphasized in past sports evaluation. At present, scientific evaluation and motivation are emphasized. For example, the sports new curricular reform requires that students' performance can be comprehensively evaluated through students' self-evaluation, students' mutual evaluation and teachers' evaluation.

\section{B. Suggestions}

Attention from the leaders of various levels, especially the school masters must be actively sought. Leaders play a key role and school masters play a decisive role in the success of the curricular implementation. Only support for and attention to sports are given and paid by the leaders

Physical education teachers should actively participate in the sports new curricular reform, for they are the major force and pioneers of the reform. They should be the first ones to "plunge into the reform" to make utmost efforts for the effective implementation of the new sports curricular reform and they should drop the teaching conception and grasp the latest teaching conception and method to adjust to the needs of the new curricular reform. They should evolve from the "managers" in the traditional "teacher-based" physical education mode into the "introducers", from the "disseminators" into the "promoters" to fully tap the potential of the students. New curricular resources should be developed and exploited. Active development should be made in and top priority should be given to various kinds of school curricular resources. Integration of curricular resources inside and outside the school should be realized and activities with sports and health themes should be actively conducted.

Construction of the physical education teaching and researching team should be reinforced in the school level. Management work concerning the new curricular implementation should be well done. School masters are directly responsible for the new curricular implementation and leaders responsible for the physical education teaching and researching should start with the management goal, plan, organization, implementation, regulation, evaluation and assessment to devise a working scheme to orderly manage the curricular implementation.

Physical education teaching contents should be reasonably selected. Physical education teachers should select the teaching contents according to the present teaching resources of their schools to secure students' all-round development and meanwhile give them as much freedom as possible in choosing the contents they want to learn.

\section{REFERENCES}

Ever since China carried out the new reform in the fundamental education curriculum in 2001, great achievements have been made in the curricular reform of "Sports and Health" [1]. When it comes to the property of the sports new curriculum, three features, namely, fundamentalness, practicability and comprehensiveness are highlighted in the "Standard for the Curriculum of 'Sports and Health' in General High Schools” [2]. The brand-new curricular conception for the sports new curricular reform is embodied in the following four aspects [3]. In terms of the teaching content, national and folk sports activities and newly rising sports events are introduced into physical education classes [4]. It is required that high school students 
earn eleven credits in their three-year high school learning [5].

[1] Z. Songgao, ed. School Sports Science. Beijing: People's Sports Publishing House, 2004, p. 5.

[2] J. Liu, H. Zengyun, ed. Outlook for Sports Education. Shanghai: Eastern China Normal University Press, 2002, p. 2.
[3] The Education Ministry. Curricular Plan for General High Schools (Trial Version). Beijing: People’s Sports Publishing House, 2003, p. 4.

[4] Textbook Research and Development Center of Sports Courses. Sports and Heath (The Teachers' Book). Beijing: People's Sports Publishing House, 200e, p. 4.

[5] The Education Ministry. Curricular Plan for General High Schools (Trial Version). Beijing: People’s Sports Publishing House, 2010, p. 